\title{
OPTIMALISASI PELAKSANAAN PROGRAM JAMINAN KESEHATAN NASIONAL MELALUI PENINGKATAN DAN PENGUATAN LAYANAN FASILITAS KESEHATAN PRIMER DENGAN PENDEKATAN GATE KEEPER IN MANAGED CARE DALAM RANGKA PENCAPAIAN UNIVERSAL HEALTH COVERAGE DI KOTA MALANG
}

\author{
Eko Aristanto ${ }^{1 *}$, Christina $\mathrm{SR}^{1}$, Krisnawuri $\mathrm{H}^{1}$ \\ ${ }^{1}$ Fakultas Ekonomi dan Bisnis Universitas Merdeka Malang \\ *aristanto90@yahoo.co.id
}

\begin{abstract}
As the site of the first level of health care, Puskesmas has a role that is essential for the success of JKN in Indonesia. Therefore, the success of JKN largely determined by Puskesmas, in particular towards healing a patient that can covered in Puskesmas, which do not need to get a reference to the hospital (Rumah Sakit).

The main purpose of this study is : the first, identify the availability of medical and non-medical personnel at the primary level health facility, identify the characteristics of the national healthcare services at the primary level health facility, identify the conditions of the existance health service of facilities and infrastructure at the primary level health facilities. Second, identify procedure and delivery system capital funding on the primary level health facility, identify the constraints and barriers to health services at the primary level health facility, identify the membership of national health coverage, identify related community perceptions of health services at the primary level health facility, based on these two steps, then strategize implementation of optimization of national health Assurance Program through the enhancement and strengthen of primary health facilities services with the approach of the Gate Keeper in Managed Care in the framework of the attainment of Universal Health Coverage in Malang City.

The design of this research is the combination of various research methods which include descriptif research, policy research and action research. Based on the research results, there are still some obstacles and constraints of Puskesmas as the first level health facilities $\quad:$ a) aspects of the service , b) aspects of human resources, c) aspects of management, d) aspects of facilities and infrastructure.
\end{abstract}

Keywords: Gate Keeper, National Health Coverage 


\section{PENDAHULUAN}

Amanat Undang-Undang Dasar 1945 dan Undang-Undang Nomor 40 tahun 2004, tentang Sistem Jaminan Sosial Nasional (SJSN) menjadikan landasan baru bagi pemerintah dalam rangka memberikan jaminan sosial bagi masyarakat indonesia. Melalui Undang-Undang nomor 24 tahun 2011, tentang Badan Penyelenggara Jaminan Sosial (BPJS), Pemerintah Indonesia melaksanakan Jaminan Kesehatan Nasional mulai tahun 2014, demi tercapainya jaminan kesehatan semesta. Salah satu program jaminan kesehatan dalam Sistem Jaminan Sosial Nasional adalah upaya kesehatan perorangan yang bersifat komprehensif dan bermutu, mencakup aspek promotif, preventif, kuratif, rehabilitatif.

Penyelenggaraan Jaminan Kesehatan Nasional memerlukan penyiapan sisi demand dan supply. Pelaksanaan jaminan kesehatan tidak hanya akan menata subsistem pembiayaan kesehatan, subsistem pelayanan kesehatan, subsistem sumber daya manusia, subsistem farmasi dan alat kesehatan, serta subsistem regulasi, sehingga terjadi harmoni antara semua subsistem dan mendukung pelaksanaan jaminan kesehatan agar berjalan baik.Dengan diselenggarakannya satu sistem jaminan kesehatan bagi seluruh penduduk pada tahun 2014, maka berbagai jenis jaminan kesehatan akan melebur ke dalam Jaminan Kesehatan Nasional. Untuk maksud tersebut dilakukan penyiapan oleh semua pihak yang meliputi penyiapan: 1) fasilitas kesehatan, sistem rujukan dan infrastruktur, 2) pembiayaan dan transformasi program serta kelembagaan, 3) regulasi, 4) sumber daya manusia dan capacity building, 5) kefarmasian dan alat kesehatan, serta 6) sosialisasi dan advokasi. ( Kementerian Kesehatan, 2012)

Sejak diimplementasikan 1 Januari 2014, minat masyarakat mendaftar sebagai peserta JKN masih tinggi. Layanan jaminan kesehatan itu tidak hanya dimanfaatkan masyarakat kurang mampu, tetapi kini juga dilirik kalangan masyarakat menengah sebagai jaminan kesehatan agar tak jatuh miskin jika sakit. Namun, dalam setahun penyelenggaraan Jaminan Kesehatan Nasional, berbagai persoalan masih membelit pelaksanaan Jaminan Kesehatan Nasional. Berbagai persoalan pelaksanaan Jaminan Kesehatan Nasional, berdasarkan Data Pers Dewan Jaminan Sosial Nasional (17 Desember 2014) antara lain : Satu, Sisi Peserta meliputi a) tidak tahu lokasi fasilitas kesehatan tingkat pertama, b) enggan berobat ke puskesmas, c) baru mendaftar saat sakit, d) bayar iuran saat sakit, setelah sembuh berhenti bayar, e) ikut kepesertaan kelas III, waktu sakit naik kelas perawatan, f) perusahaan enggan mendaftarkan pekerjanya. Dua, sisi Puskesmas meliputi a) peralatan diagnostik tak lengkap, b) belum semua mampu tangani 155 jenis penyakit. Tiga, sisi Rumah Sakit meliputi a) sebagian minta pasien naik kelas perawatan, b) sebagian minta pasien bayar uang muka dan beli obat sendiri, c) antrean operasi dan perawatan panjang, d) kapasitas sejumlah RS terbatas, e) Kepesertaan RS swasta rendah, f) RS di daerah kekurangan dokter spesialis Empat, sisi BPJS Kesehatan meliputi a) antrean pendaftaran masih panjang di daerah dan b) sosialisasi JKN ke peserta, calon peserta dan calon RS lemah. Lima, sisi Program meliputi : a) tumpang tindih dengan jaminan kesehatan daerah, b) sejumlah pemerintah daerah menunggak iuran askes periode sebelumnya, c) sebagaian masyarakat tak paham sistem perbankan, dan d) menyuburkan percaloan.

Pelayanan kesehatan yang diberikan meliputi promotif, preventif, kuratif dan rehabilitative, termasuk pelayanan obat dan bahan medis habis pakai sesuai kebutuhan medis. Sistem pelayanan berdasarkan sistem rujukan berjenjang, yang dimulai dari Pusat Pelayanan Kesehatan Tingkat Pertama (Puskesmas, Praktek Dokter/Dokter Gigi, 
Klinik Pratama, RS kelas D Pratama), kemudian ke RS kelas D/C, selanjutnya ke RS kelas B, dan yang terakhir ke RS kelas A. Namun demikian, Pusat Pelayanan Kesehatan Tingkat Pertama yang dituju oleh sebagian besar masyarakat dalam mendapatkan pengobatan, adalah Pusat Kesehatan Masyarakat (Puskesmas). Sebagai tempat pelayanan kesehatan tingkat pertama, Puskesmas memiliki peranan yang sangat penting bagi keberhasilan program JKN di Indonesia. Oleh sebab itu, keberhasilan Program JKN sangat ditentukan oleh Puskesmas, khususnya terhadap kesembuhan pasien yang cukup ditangani di Puskesmas, yang tidak perlu mendapat rujukan ke RS. Puskesmas, akan dapat memberikan pelayanan sebaik-baiknya jika dilengkapi dengan sarana dan prasarana yang dibutuhkan, diantaranya tersedianya SDM, alat-alat kesehatan, dan fasilitas kesehatan lainnya. Namun, faktor terpenting adalah tersedianya SDM, karena tanpa tersedianya SDM, sumber-sumber lain tidak dapat digunakan secara optimal.

Kota Malang adalah sebuah kota di Provinsi Jawa Timur, Indonesia. Kota ini berada di dataran tinggi yang cukup sejuk, terletak $90 \mathrm{~km}$ sebelah selatan Kota Surabaya, dan wilayahnya dikelilingi oleh Kabupaten Malang. Secara administratif, Kota Malang terbagi menjadi lima kecamatan (Kedungkandang, Sukun, Klojen, Blimbing dan Lowokwaru) dan 57 (lima puluh Tujuh) kelurahan. Kota malang dengan jumlah penduduk hingga saat ini 820.243 jiwa, merupakan kota terbesar kedua di Provinsi Jawa Timur setelah Surabaya. Dengan jumlah penduduk yang banyak maka ketersediaan sarana dan prasarana kesehatan juga harus berbanding linier. Berdasarkan data Dinas Kesehatan Kota Malang menunjukan bahwa jumlah fasilitas kesehatan berjumlah 99 fasilitas kesehatan.

Jumlah penduduk di Kota Malang lokasi sebanyak 820.243 jiwa. Dari jumlah tersebut yang menjadi peserta JKN sebanyak 372.710 jiwa (45,44\%). Kepesertaan tersebut secara umum masih didominasi oleh PBI dan Pegawai Negeri Sipil (PNS), TNI dan Polri serta keluarganya. Kepesertaan PBI dan PNS/TNI/Polri merupakan kepesertaan dari PT. Askes yang migrasi ke kepesertaan BPJS Kesehatan. Kecenderungan masyarakat umum atau kelompok mandiri mendaftar menjadi kepesertaan BPJS merupakan hal yang sangat mengembirakan. Ini menunjukkan kesadaran masyarakat akan pentingnya melakukan pengelalolan risiko akibat kondisi kesehatan. Namun cakupan tersebut masih relatif belum memuaskan, menginggat hampir 54,56\% penduduk Malang masih belum tercover dalam Program Jaminan Kesehatan Nasional (JKN). Dengan memperhatikan perkembangan Program Jaminan Kesehatan Nasional (JKN) di Kota Malang, dalam rangka upaya menuju Universal Health Coverage tentunya membutuhkan berbagai kajian dan upaya nyata yang harus dilakukan oleh pemerintah daerah. Penyediaan jaminan kesehatan yang merupakan amanat UU Sistem Jaminan Sosial Nasional dapat dicapai dalam rangka peningkatan kesejahteraan masyarakat.

\section{TINJAUAN PUSTAKA}

\section{Konsep Jaminan Kesehatan Nasional dalam Sistem Jaminan Sosial Nasional.}

Jaminan kesehatan merupakan salah satu komponen dari sub sistem pendanaan kesehatan. Sub sistem pendanaan kesehatan merupakan bagian dari Sistem Kesehatan Nasional (SKN). Dengan demikian pengembangan jaminan kesehatan tidak bisa dilepaskan dari sistem kesehatan secara keseluruhan yang tujuan akhirnya adalah tercapainya derajat kesehatan penduduk Indonesia yang memungkinkan penduduk produktif dan kompetitif dengan penduduk negaranegara tetangga (Kementerian Kesehatan, 
2012).

Sistem Kesehatan Nasional pada prinsipnya terdiri dari dua bagian besar yaitu sistem pendanaan dan sistem layanan kesehatan. Subsistem pendanaan kesehatan menggambarkan dan mengatur sumber-sumber keuangan yang diperlukan untuk terpenuhinya kebutuhan kesehatan penduduk. Pendanaan kesehatan dapat bersumber dari (1) pendanaan langsung dari masyarakat (disebut out of pocket) yang dibayarkan dari perorangan/rumah tangga kepada fasilitas kesehatan; (2) pendanaan dari Pemerintah dan atau Pemda; (3) pembayaran iuran asuransi sosial yang wajib sebagaimana diatur dalam UU SJSN; (4) Pendanaan oleh pihak ketiga, baik oleh pemberi kerja atau oleh peserta asuransi; dan (5) bantuan pendanaan dari berbagai sumber baik dalam maupun luar negeri. Berdasarkan UU Nomor 40/2004 tentang SJSN dan UU Nomor 36/2009 tentang Kesehatan, pendanaan layanan kesehatan perorangan akan bertumpu dari iuran wajib yang akan dikelola oleh BPJS Kesehatan. Sementara pendanaan bersumber dari kantong perorangan/keluarga, pemberi kerja baik langsung atau melalui asuransi kesehatan swasta akan menjadi sumber dana tambahan (top up) layanan kesehatan perorangan. Sedangkan sumber dana dari Pemerintah/Pemda tetap diperlukan untuk mendanai bantuan iuran bagi penduduk miskin dan tidak mampu serta pendanaan program kesehatan masyarakat yang tidak ditujukan untuk layanan orang per orang.

Gambar 1 : Tiga Dimensi Pencapaian UniversalCoverage

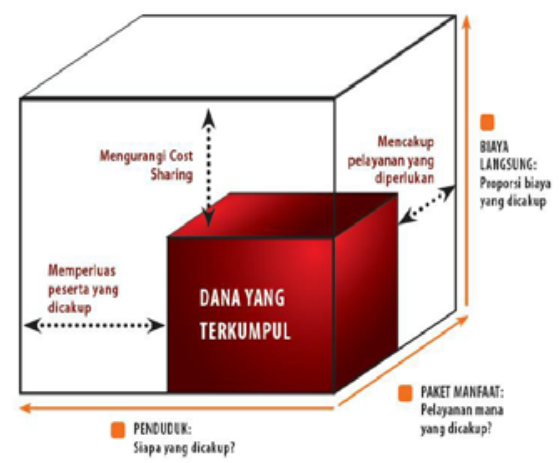

WHO merumuskan tiga dimensi dalam pencapaian universal coverage yaitu (1) seberapa besar prosentase penduduk yang dijamin; (2) seberapa lengkap pelayanan yang dijamin, serta (3) seberapa besar proporsi biaya langsung yang masih ditanggung oleh penduduk. Dimensi pertama adalah jumlah penduduk yang dijamin. Dimensi kedua adalah layanan kesehatan yang dijamin, misalnya apakah hanya layanan di rumah sakit atau termasuk juga layanan rawat jalan. Dimensi ketiga adalah proporsi biaya kesehatan yang dijamin. Dapat saja seluruh penduduk dijamin biaya perawatan di rumah sakit, tetapi setiap penduduk harus bayar sebagian biaya di rumah sakit. Perluasan jaminan ketiga dimensi sangat tergantung pada kemampuan keuangan suatu negara dan pilihan penduduknya.

Konsentrasi pertama adalah bagaimana agar dimensi pertama tercapai yaitu semua penduduk terjamin sehingga setiap penduduk yang sakit tidak menjadi miskin karena beban biaya berobat yang tinggi. Langkah berikutnya adalah memperluas layanan kesehatan yang dijamin agar setiap orang dapat memenuhi kebutuhan medis (yang berarti semakin komprehensif paket manfaatnya). Terakhir adalah peningkatan biaya medis yang dijamin sehingga makin kecil proporsi biaya langsung yang ditanggung penduduk.

Sesuai dengan pengalaman masa lalu dan pengalaman penyediaan jaminan kesehatan untuk pegawai negeri, maka Indonesia menghendaki jaminan kesehatan untuk semua penduduk (dimensi I), menjamin semua penyakit (dimensi II), dan porsi biaya yang menjadi tanggungan penduduk (dimensi III) sekecil mungkin. Namun demikian, tingkat kenyamanan (kepuasan/pilihan) layanan dibatasi. Sebagai contoh, Askes PNS menjamin layanan perawatan di kelas II RS publik (untuk golongan pangkat I dan II) dan di kelas I RS publik (untuk golongan pangkat III dan IV). Tingkat 
pilihan/kepuasan dibatasi dengan kelas perawatan, tetapi semua penyakit atau semua biaya perawatan dijamin apabila peserta Askes dirawat sesuai kelas perawatan yang menjadi haknya. Jika peserta menginginkan perawatan di ruang kelas yang lebih memuaskan, kelas VIP, maka peserta Askes harus membayar selisih biayanya (dimensi III). Dengan demikian, sistem jaminan/asuransi pegawai negeri menjamin pemenuhan kebutuhan medis dengan biaya terkendali, meskipun sebagian tidak puas dengan kelas perawatan. Yang utama adalah pemenuhan kebutuhan medis seluruh penduduk (dimensi I) dan seluruh penyakit dijamin (dimensi II).

\section{Prinsip-prinsip dan Konsep Pengelolaan Jaminan Kesehatan Nasional.}

Program Jaminan Kesehatan

Nasional (JKN) yang dikembangkan di Indonesia merupakan bagian dari Sistem Jaminan Sosial Nasional (SJSN) yang diselenggarakan melalui mekanisme asuransi sosial yang bertujuan agar seluruh penduduk Indonesia terlindungi dalam sistem asuransi sehingga mereka dapat memenuhi kebutuhan dasar kesehatan. Dengan mengacu pada UU No. 40/2004 tentang Sistem Jaminan Sosial Nasional dan UU No. 24/2011 tentang BPJS Kesehatan. Pasal 18 UU No. 40/2004 menyatakan jenins program jaminan sosial meliputi a. Jaminan Kesehatan, b. Jaminan Kecelakaan Kerja, c. Jaminan Hari Tua, d. Jaminan Pensiun dan e. Jaminan Kematian. Pasal 19 (1) menyebutkan : “ a. Jaminan kesehatan; b. Jaminan kecelakaan kerja; c. Jaminan hari tua; d. Jaminan pensiun; dan e. Jaminan kematian. Dalam pasal 19 (1) menyebutkan “ Jaminan kesehatan diselenggarakan secara nasional berdasarkan prinsip asuransi sosial dan prinsip ekuitas”. Pada penjelasan pasal 19 (1) dituliskan : "Prinsip asuransi sosial meliputi : a) Kegotongroyongan antara lain orang kaya dan miskin, yang sehat dan sakit, yang tua dan muda, yang berisiko tinggi dan rendah; b) Kepesertaan bersifat wajib dan tidak selektif; c) Iuran berdasarkan presentase upah/penghasilan, d). Bersifat Nir Laba.

Dalam pelaksanaan program Jaminan Kesehatan Nasional (JKN), Badan Penyelenggara Jaminan Sosial Kesehatan (BPJS Kesehatan) mengacu pada prinsipprinsip sebagaimana diamanatkan dalam Undang-Undang Nomor 40 Tahun 2004 tentang Sistem Jaminan Sosial Nasional (SJSN), yaitu:

Tabel 1

Prinsip-prinsip Pelaksanaan Jaminan Kesehatan Nasional

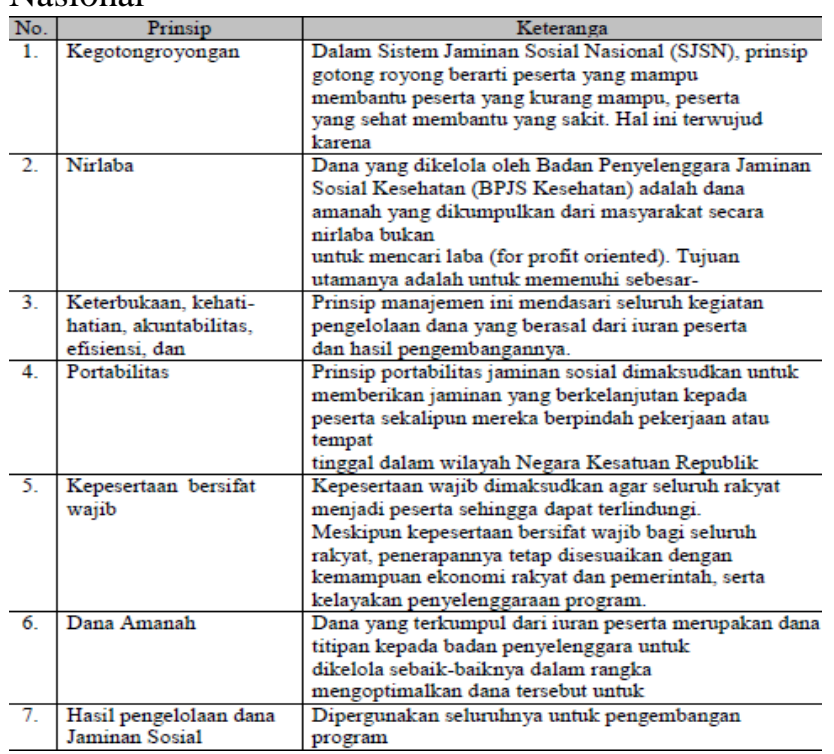

Sumber : Peraturan Menteri Kesehatan No. 28

Tahun 2014

\section{Pendekatan Gate Keeper in Managed Healthcare dalam Program Jaminan Kesehatan Nasional}

Konsep managed healthcare dalam penyelenggaraan jaminan kesehatan dapat diatikan sebagai keterpaduan antara pelayanan kesehatan yang bermutu dan pembiayaan terkendali. Pelayanan kesehatan meliputi promotif, preventif, kuratif dan rehabiltatif dengan pola pembiayaan yang dapat mengendalikan kenaikan biaya pelayanan antara dengan pembayaran sistem kapitasi, paket pradana atau prospective payment system dan pelayanan 
kesehatan berjenjang. Konsep ini memungkinkan kualitas pelayanan dan pembiayaan kesehatan dapat diselenggarakan seefisien mungkin, tidak boros, mencegah pemakaian yang berlebihan (over utilization) atau pemberian pelayanan kesehatan yang tidak perlu (unnecessary untilization), bahkan kemungkinan penyalahgunaan (abuse of care). Untuk itu, perlu pemahaman, disiplin dan dukungan semua pihak terkait, baik peserta maupun pemberi pelayanan kesehatan (kalangan dokter dan rumah sakit). Begitu pentingnya introduksi managed healthcare itu, dalam UU No. 20 tahun 2004 termaktud prosedur-prosedur dan prinsip-prinsip yang perlu dilaksanakan. Intinya, antara sistem pelayanan dan pembayaran diintegrasikan. Sistem pelayanan diselenggarakan secara berjenjang sehingga sesuai keahlian dan teknologi kedokteran yang diperlukan. Kebebasan peserta untuk memperoleh layanan kesehatan ditertibkan melalui konsep dokter keluarga dan rujukan. Kebebasan peserta untuk memperoleh pelayanan kesehatan ditertibkan melalui dokter keluarga dan rujukan. Pembayaran jasa pelayanan kesehatan diselenggarakan dengan menghapus sistem fee for services yang telah kita kenal selama ini, dengan memperkenalkan pembayaran sistem kapitasi, paket pradana atau prospective payment system.

Gambar 2. Prosedur Pelayanan Kesehatan Program Jaminan Kesehatan Nasional Sumber : BPJS Kesehatan, 2014

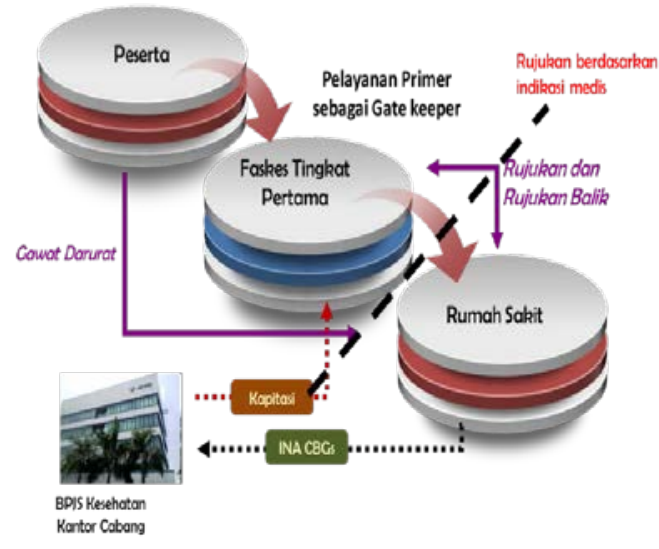

Demikian juga obat-obatan, yang selama ini merupakan porsi yang besar di dalam pembiayaan kesehatan, perlu dilakukan kontrol khasiat dan harganya. Diberlakukan semacam daftar standar dan plafon harga obat sehingga pengunaan obat rasional, tidak berlebihan dan tidak kurang.Dengan konsep pelayanan semacam ini pelayanan kesehatan yang diberikan sesuai kebutuhan medik pasien, bukan keingginan perorangan. Dengan efisiensi seperti itu, biaya pelayanan kesehatan dapat terselenggara secara optimal, tidak boros sebagaimana sistem fee for services yang ada selama ini. Adapun gate keeper in managed care dapat didefinisikan sebagai dokter yang berwenang mengatur pelayanan kesehatan bagi peserta, sekaligus bertanggung jawab dalam rujukan pelayanan kesehatan lanjutan sesuai kebutuhan medis peserta. Adapun tugas gate keeper dalam managed care adalah : a) menyelenggarakan pelayanan kesehatan dasar untuk memenuhi kebutuhan kesehatan peserta secara paripurna, terpadu dan bermutu; b) mengatur pelayanan kesehatan lanjutan melalui sistem rujukan; c) penasehat, konselor dan pendidik untuk mewujudkan keluarga sehat; d) manajer sumberdaya. Sedangkan fungsi gatekeeper adalah menjaga masyarakat, keluarga, individu tetap sehat dengan memperhatikan pola hidup sehat, menjauhkan at risk, individual/mass screening, diagnosa dini, prompt treatment dan rehabilitasi.

\section{Penelitian Pendahuluan Penelitian Yang Relevan}

Kehadiran Program Jaminan Kesehanan Nasional (JKN) memberikan harapan baru bagi masyarakat yang selama ini mengeluhkan mahalnya biaya kesehatan di negeri ini. Disamping itu, melalui Program Jaminan Kesehatan Nasional upaya peningkatan kualitas pelayanan kesehatan terus berbenah sesuai dengan ketentuan yang berlaku. 
Beberapa penelitian yang dapat menjadi acuan awal adalah penelitian dengan judul "Survei Nasional Kepuasan Peserta dan fasilitas Kesehatan BPJS Kesehatan 2014" dilakukan oleh Myriad tahun 2014 di 24 Kabupaten/Kota dengan jumlah responden 17.280 responden. Hasil penelitian menunjukkan bahwa ada kecenderungan Fasilitas Kesehatan non pemerintah memiliki tingkat kepuasan yang sedikit lebih tinggi dari Fasilitas kesehatan pemerintah, baik di tingkat Fasilitas Kesehatan Tingkat Pertama (FKTP) maupun di tingkat Fasilitas Kesehatan Tingkat Lanjutan (FKTL). Sedangkan berkaitan dengan tingkat kepuasan menunjukkan 81\% Peserta BPJS Kesehatan menyatakan puas dengan pelayanan yang diberikan oleh fasilitas kesehatan dan BPJS Kesehatan.

Penelitian senada juga dengan judul "Kajian Kesiapan Puskesmas dalam Pelaksanaan Pelayanan Kesehatan Program Jaminan Kesehatan nasional" dilakukan oleh Tim Nasional Percepatan Penanggulangan Kemiskinan (TNP2K) Republik Indonesia tahun 2014. Hasil penelitian tersebut memberikan kesimpulan Pada umumnya puskesmas relatif siap memberikan pelayanan kesehatan program JKN, meskipun masih menghadapi kendala diantaranya i) Kekurangan tenaga kesehatan untuk jenis/profesi/jabatan tertentu, terutama dokter gigi, farmasi/apoteker, analis kesehatan, keterapian fisik, tenaga gizi, dan keteknisan medis, ii Seluruh Puskesmas menghadapi keterbatasan obatobatan, laboratorium dan alat kesehatan, sehingga menyebabkan pelayanan penegakan terhadap 155 diagnosa penyakit yang diharapkan dapat ditangani di tingkat puskesmas tidak dapat diberikan secara menyeluruh, iii) Belum tersedia jaringan internet, keterbatasan perangkat komputer, dan tidak adanya SDM yang menguasai teknologi informasi sehingga berdampak pada kesulitan dalam pengoperasian aplikasi sistem informasi manajemen
P-Care.

\section{METODE PENELITIAN}

\section{Rancangan Penelitian}

Rancangan penelitian ini merupakan kombinasi dari berbagai metode penelitian yang meliputi penelitian desktriptif, penelitian kebijakan (policy research) dan penelitian tindakan (action research). Dalam penelitian ini pendekatan partisipatif dilakukan dengan menekankan pada pelibatan berbagai aktor utama dalam program jaminan kesehatan nasional. Pendekatan partisipatif ini diterapkan pada tahap pengumpulan informasi melalui Workshop, FGD, dan wawancara. Adapun obyek penelitian meliputi ; 1) Kepala puskesmas, 2) Dokter puskesmas, 3) Dinas Kesehatan, 4) Badan Pelaksana Jaminan Sosial (BPJS) Kesehatan, 5) Bappeda dan 6) stakeholder terkait sebagai pendukung program Jaminan Kesehatan Nasional di Kota Malang. Sedangkan metode sampling yang digunakan purposive sampling dan mendasarkan kerangka sampling yang telah disusun sesuai dengan kriteria yang ditetapkan pada masing- masing obyek penelitian. Metode analisis yang digunakan dalam penelitian ini adalah MPA (Methodology for Partisipatory Assesment) dan Metode ZOPP (Ziel Oriertierte Project Planning) yang disesuaikan dengan tujuan penelitian. Dalam rangka menghasilkan strategi optimalisasi, roadmap dan naskah kebijakan tentang Jaminan Kesehatan Nasional di Kota Malang. penelitian ini dibagi dalam dua tahapan penelitian yang setiap tahapan dilaksanakan selama satu tahun anggaran. Adapun tahapan penelitian tersebut meliputi : 


\section{HASIL PENELITIAN}

\section{Karakteristik Pelayanan Kesehatan Program Jaminan Kesehatan Nasional pada Puskesmas Kota Malang.}

Dalam Peraturan Menteri Kesehatan Republik Indonesia No. 71 Tahun 2013 tentang Pelayanan Kesehatan pada Jaminanan Kesehatan Nasional menjelaskan bahwa Fasiltas Kesehatan Tingkat Pertama (FKTP) merupakan tempat pelayanan kesehatan perorangan yang bersifat non spesialistik (primer) meliputi pelayanan rawat jalan dan rawat inap. Untuk pelayanan rawat jalan hanya untuk keperluan observasi, diagnosis, pengobatan, dan/atau pelayanan kesehatan lainnya. Sedangkan pelayanan rawat inap untuk keperluan observasi, perawatan, diagonisis, pengobatan, dan/atau perawatan medis lainnya, dimana peserta dan/atau anggota keluarganya dirawat inap paling singkat 1 (satu) hari. Adapun dalam Program Jaminan Kesehatan Nasional (JKN) untuk Fasilitas Kesehatan Tingkat Pertama (FKTP) antara lain : Puskesmas, Praktek Dokter, Praktek Dokter Gigi, Klinik Pratama dan Rumah Sakit Tipe D.

Dalam pelayanan kesehatan Program Jaminan Kesehatan Nasional (JKN) yang menjadi fokus sampel kajian adalah Puskesmas. Puskesmas atau Pusat Kesehatan Masyarakat adalah unit pelaksana teknis dinas kesehatan kabupaten/kota yang bertanggung jawab menyelenggarakan pembangunan kesehatan di suatu wilayah kerja. Sebagai penyelenggara pembangunan kesehatan, puskesmas bertanggung jawab menyelenggarakan upaya kesehatan perorangan dan upaya kesehatan masyarakat, yang di tinjau dari Sisten Kesehatan Nasional merupakan pelatanan kesehatan tingkat pertama (Depkes RI, 2009). Pada saat ini puskesmas telah didirikan hampir di seluruh pelosok tanah air. Untuk menjangkau wilayah kerjanya puskesmas diperkuat dengan puskesmas pembantu, puskesmas keliling dan untuk daerah yang jauh dari sarana pelayanan rujukan, puskesmas dilengkapi dengan fasilitas rawat inap. Dalam pelaksanaan kajian dilaksanakan Kota Malang terpilih dengan sampel fasilitas kesehatan primer yang dikunjungi sebanyak 15 puskesmas.

Pelayanan kesehatan dasar bagi peserta Jaminan Kesehatan Nasional (JKN) dapat dilakukan pada Puskesmas wilayah terdekat. Berkaitan dengan pelayanan kesehatan masyarakat, maka puskesmas memiliki 2 (dua) kategori yakni puskesmas dengan pelayanan non rawat inap dan puskesmas dengan pelayanan rawat inap. Dalam kegiatan kajian ini, puskesmas selaku Fasilitas Kesehatan Tingkat Pertama (FKTP) dapat diklasifikasikan ke dalam 2 (dua) jenis puskesmas dengan mendasar tingkat pelayanan yakni $5 \quad(33,3 \%)$ puskesmas rawat inap dan 10 (66,6\%) puskesmas non rawat inap. Keberadaan puskesmas rawat inap sangat membantu pelayanan kesehatan tingkat primer bagi masyarakat yang sangat jauh dari jangkauan fasiltas kesehatan. Untuk puskesmas di daerah yang relatif padat penduduk dan akses ke sarana kesehatan lainnya sangat sulit, maka puskesmas dapat berperan dapat berperan sebagai pusat pelayanan kesehatan rawat jalan dan rawat inap. Pelayanan kesehatan di tingkat puskesmas masih membayar, menginggat kemampuan pemerintah daerah dalam penyediaan anggaran kesehatan yang bersumber dari APBD sangat minim dan namun bagi peserta JKN gratis bagian komitmen bagi penerintah daerah dalam pelayanan kesehatan tingkat primer. 
Gambar 1

Sebaran Puskesmas di Kota Malang

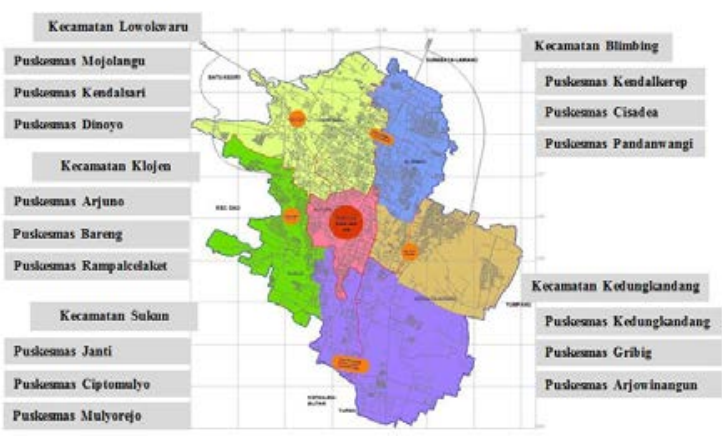

Sumber : Data Sekunder, diolah (2016)

Puskesmas sebagai pelayanan kesehatan primer yang terjangkau dan masih dibutuhkan masyarakat, serta berperan penting bagi implementasi program Jaminan Kesehatan Nasional (JKN). Hal tersebut tidak terlepas fungsinya sebagai gate keeper atau penentu apakah peserta membutuhkan rujukan ke fasilitas kesehatan sekunder (seperti klinik dokter spesialis dan rumah sakit) atau tidak. Salah satu bagian penting dalam pelayanan kesehatan di tingkat puskesmas adalah jadwal dan waktu pelayanan puskesmas yang menjelaskan tentang kepastian pelayanan di setiap puskesmas.

Jadwal pelayanan kesehatan bagi pasien di tingkat puskesmas untuk hari Senin s.d Kamis sebanyak 7 (tujuh) per hari. Untuk pelayanan kesehatan bagi pasien hari Jumat sebanyak 4 (empat) jam perhari, dan hari Sabtu sebanyak 6 (enam) jam perhari. Jumlah jam pelayanan di puskesmas yang semakin banyak menentukan bagi akses pasien untuk dapat mendapat kepastian pelayanan kesehatan. Namun untuk pelayanan kesehatan bagi pasien yang terletak pada daerah yang terpencil dan dokter dan perawat berada dalam wilayah tersebut, maka jam pelayanan kesehatan pada puskesmas dapat dilakukan setiap saat sewaktu-waktu. Manakala terdapat pasien yang mendadak untuk segera di tanggani di tenaga medis dan non medis yang ada di puskesmas tersebut.

Dengan pelayanan kesehatan bagi pasien di tingkat puskesmas yang telah terjadwal, maka pelayanan kesehatan pada para pasien dapat dioptimalkan selama rentang jam pelayanan. Jam pelayanan juga sangat berpengaruh terhadap jumlah pasien yang dapat di tangani secara rata-rata perhari oleh dokter dan perawat di puskesmas. Namun jumlah pasien yang dapat ditangani oleh dokter dan perawat di puskesmas, juga sangat dipengaruhi faktor jarak antara rumah dengan puskesmas. Hasil penelitian TNP2K menjelaskan fakta menunjukkan bahwa 94,2\% rumah tangga dapat mengakses fasilitas kesehatan dalam jarak kurang hari $5 \mathrm{~km}$ dan 97,4\% rumah tangga dapat mengakses fasilitas kesehatan dalam waktu kurang dari 60 menit.

Harus diakui bahwa kondisi pelayanan puskesmas di lokasi kajian, dilihat dari sebaran dan kualitas layanan kesehatan memang belum baik dan belum memenuhi harapan banyak pihak. Sebaran fasilitas kesehatan dan dokter masih terkonsentrasi pada daerah-daerah yang jumlah penduduknya padat. Pada puskesmas yang berada pada daerah dengan kepadatan penduduk yang tinggi tentunya jumlah pasien yang membutuhkan pelayanan kesehatan semakin banyak dan sebaliknya. Hal tersebut dapat ditemui pada 4 puskesmas yang jumlah pasien harian yang dapat dilayani perhari melebihi 150 pasien perhari. Pelayanan kesehatan di puskesmas dengan adanya program Jaminan Kesehatan Nasional (JKN) tentunya akan menjadikan beban tambahan bagi para tenaga medis dan non medis, hal tersebut dikarenakan masih belum adanya sistem penghubung antara BPJS Kesehatan dan Puskesmas untuk melakukan pemantauan terhadap terhadap sistem administrasi pelayanan kesehatan di tingkat puskesmas.

\section{Kondisi Ketersediaan Tenaga Medis dan Non Medis pada Puskesmas Kota Malang}

Dalam pelayanan kesehatan di Fasilitas Kesehatan Tingkat Pertama (FKTP) keberadaan dan dukungan Sumber Daya Manusia Kesehatan (SDMK) yang meliputi Tenaga Medis dan Tenaga Non 
Medis sangat penting. Adapun ketentuan yang berlaku di tingkat Puskesmas harus memiliki Sumber Daya Manusia Kesehatan (SDMK) yang tenaga tetap meliputi tenaga medis dan penunjang medis, tenaga keperawatan, tenaga kefarmasian dan tenaga non kesehatan. Secara umum ketersedian tenaga medis dan non medis pada tingkat puskesmas telah teridentifikasi dalam data Rifaskes 2011, namun demikian dalam kajian juga melakukan pendataan ulang sesuai kondisi lapangan.

Tabel 2.

Data Rasio SDM Kesehatan berbanding Jumlah Penduduk per Puskesmas.

\begin{tabular}{|c|c|c|c|c|c|c|c|c|}
\hline \multirow{3}{*}{$\begin{array}{l}\text { No. } \\
1 \\
\end{array}$} & \multirow{3}{*}{$\begin{array}{c}\text { Puskesmas } \\
\text { Kedungkandang }\end{array}$} & \multicolumn{6}{|c|}{ Perbandingan } & \multirow{3}{*}{$\begin{array}{r}\text { Keterangan } \\
\text { Kurang } \\
\end{array}$} \\
\hline & & \multicolumn{3}{|c|}{$\begin{array}{c}\text { Jumlah Dokter } \\
\text { Umum : Jumlah } \\
\text { Penduduk }\end{array}$} & \multicolumn{3}{|c|}{$\begin{array}{l}\text { Pelayanan Per } \\
\text { Dokter Umum }\end{array}$} & \\
\hline & & 7 & & 183.927 & 1 & : & 26.275 & \\
\hline 2 & Sukun & 6 & $:$ & 188.545 & 1 & : & 31.424 & Kurang \\
\hline 3 & Blimbing & 7 & : & 176.845 & 1 & : & 25.264 & Kurang \\
\hline 4 & Klojen & 8 & $:$ & 104.590 & 1 & : & 13.074 & Kurang \\
\hline 5 & Lowokwaru & 7 & - & 192.066 & 1 & 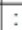 & 27.438 & Kurang \\
\hline
\end{tabular}

Sumber : data sekunder, diolah (2016)

Data lapangan menunjukkan terdapat perbedaan jumlah Sumber Daya Manusia Kesehatan (SDMK) di berbagai jabatan, jika dibandingkan data Rifaskes 2011. Untuk seluruh jabatan yang ada pada 15 puskesmas kajian, menunjukkan terdapat kekurangan SDMK. Untuk jabatan dokter spesialis pada seluruh puskesmas di lokasi kajian belum terisi/kosong. Jumlah kekurangan SDMK terbesar di 15 puskesmas kajian ada pada jabatan perawat yang mempunyai fungsi strategis dalam pelayanan kesehatan tingkat pertama dan kekurangan SDMK pada jabatan lainnya adalah tenaga kesehatan masyarakat. Ketersediaan SDMK di tingkat puskesmas, sangat penting menginggat fungsi puskesmas sebagai gate keeper. Terkait dengan fungsi gate keeper tersebut harus dibarengi dengan peningkatan kemampuan dan keterampilan tenaga medis dipuskesmas dan dibarengi dengan penyesuaian imbalan layak. Perbandingan data pada beberapa puskesmas di atas menunjukkan bahwa ketersediaan tenaga medis dan non medis sangat beragam dan penyebarannya kurang merata. Dengan kondisi tersebut, sebaran dan kualitas pelayanan kesehatan yang dilakukan di puskesmas memang belum memenuhi harapan banyak pihak. Kondisi di lapangan menunjukkan hambatan yang penting dalam pelayanan kesehatan adalah ketidak tersediaan Sumber Daya Manusia Kesehatan (SDMK) dalam jumlah, jenis, kualifikasi, serta kapabilitas yang sesuai dengan kebutuhannya nyata di lapangan dalam pelaksanaan program Jamina Kesehatan Nasional (JKN). Akan sulit bagi puskesmas dalam melaksanakan pelayanan kesehatan, apabila kompoten penting yang utama tersebut masih belum memenuhi standart pelayanan minimum yang harus dilaksanakan oleh puskesmas.

Pelayanan kesehatan yang dilakukan oleh Tenaga Medis dan Non Medis juga harus didukung dengan fasilitas layanan kesehatan yang lengkap dan terjangkau sehingga mampu melakukan diagnosis terhadap pernyakit pasien. Dengan adanya fasilitas layanan kesehatan yang lebih baik dari ketersediaan peralatan kesehatan, tenaga medis dan non medis yang handal, ketersediaan bahan medis dan bahan habis pakai, ketesediaan obat essensial maupun penampilan fisik yang memadai sangat dibutuhkan untuk memberikan pelayanan sesuai kebutuhan medis.

Berdasarkan data pada tabel di atas, menunjukkan rasio ideal antara SDM Kesehatan dengan berbanding jumlah penduduk berdasarkan Standar Kemenkes sangat jauh dibanding dengan kondisi hasil kajian. Dengan berpedoman pada standar Kemenkes, maka rasio SDM Kesehatan pada Puskesmas penelitian, tidak ada satupun yang memenuhi standar Kemenkes.

Berdasarkan Peraturan Menteri Kesehatan No. 28 Tahun 2014 tentang Pedoman Pelaksanaan Program Jaminan Kesehatan Nasional (JKN) menjelaskan kepesertaan program Jaminan Kesehatan Nasional (JKN) terdiri atas 2 kelompok yaitu : a) Peserta Penerima Bantuan Iuran (PBI) jaminan kesehatan adalah fakir miskin dan orang tidak mampu dan b) Peserta 
bukan Penerima Bantuan Iuran (PBI) jaminan kesehatan adalah pekerja penerima upah dan anggota keluarganya, Pekerja bukan penerima upah dan anggota keluarganya, serta bukan Pekerja dan anggota keluarganya. Peserta Penerima bantuan Iuran (PBI) dalam JKN dibayari pemerintah, Selain itu untuk peserta mandiri, ada 3 (tiga) kelas yang bisa dipilih peserta mandiri, yakni kelas III dengan premi Rp. 25.500 perbulan, kelas II dengan premi Rp. 42.500 perbulan dan kelas I dengan premi Rp. 59.500 perbulan.

Kondisi kepesertaan Jaminan

Kesehatan Nasional (JKN) pada 15 puskesmas di Kota Malang telah mencapai 444.051 jiwa dari jumlah penduduk di wilayah puskesmas sebanyak 845.973 jiwa (52,49\%). Kepesertaan Jaminan Kesehatan Nasional tersebut, secara umum masih didominasi data dari Penerima Bantuan Iuran (PBI) dan Pegawai Negeri Sipil (PNS) /TNI dan Polri dan keluarganya. Kepesertaan PBI dan PNS/TNI/Polri merupakan kepesertaan dari PT. Askes yang migrasi ke kepesertaan BPJS Kesehatan. Untuk data kepesertaan yang dari pegawai swasta dan bukan pegawai tidak dapat diidentifikasi dengan baik, dikarenakan keterbatasan penyediaan data di BPJS. Namun jika merujuk pada data BPJS Kesehatan menunjukkan, secara nasional jumlah peserta BPJS Kesehatan saat ini sebanyak 166 juta jiwa. Kondisi tersebut menunjukkan respon masyarakat terhadap program Jaminan Kesehatan Nasional (JKN) cukup tinggi, di tengah kesadaran bahwa pembiayaan kesehatan sangat mahal.

\section{Data Prosedur dan Mekanisme Delivery System Dana Kapitasi di Puskesmas Kota Malang}

Dalam Peraturan Menteri Kesehatan Republik Indonesia Nomor 19 Tahun 2014 menjelaskan bahwa yang dimaksud Dana Kapitasi adalah besaran pembayaran perbulan yang yang dibayar dimuka kepada Fasilitas Kesehatan Tingkat Pertama (FKTP) berdasarkan jumlah peserta yang terdaftar tanpa memperhitungkan jenis dan jumlah pelayanan kesehatan yang diberikan. Adapun keperuntukan dana kapitasi yang diterima oleh Fasilitas Kesehatan Tingkat Pertama (FKTP) dari Badan Penyelenggara Jaminan Sosial (BPJS) Kesehatan dimanfaatkan seluruhnya untuk : a) pembayaran jasa pelayanan kesehatan dan ib) dukungan biaya operasional pelayanan kesehatan. Dalam program Jaminan Kesehatan Nasional (JKN) dukungan bagi dana operasional puskesmas sangat bergantung dengan Dana Kapitasi. Secara umum besaran dana kapitasi dan alokasi pengunaan Dana Kapitasi diatur dalam Perpres No. 32/2014, Permenkes 19/2014, dan SE Mendagri.

Berdasarkan Peraturan Menteri Kesehatan Republik Indonesia Nomor 19 Tahun 2014 alokasi untuk pembayaran jasa pelayanan kesehatan untuk tiap sekurangkurangnya $60 \%$ dari penerimaan Dana Kapitasi. Alokasi Dana kapitasi untuk pembayaran jasa pelayanan kesehatan dimanfaatkan untuk pembayaran jasa pelayanan kesehatan bagi tenaga kesehatan dan tenaga non kesehatan yang melakukan pelayanan FKTP. Kondisi lapangan menunjukkan bahwa keragaman alokasi pengunaan dana kapitasi telah memenuhi ketentuan Perpres RI No. 32/2014 dan Permenkes No. 19/2014 yakni sekurangkurangnya $60 \%$ dari penerimaan Dana Kapitasi.

Dalam rangka kepastian dan proses administrasi penyaluran dana kapitasi sesuai dengan Peraturan Presiden No. 32 tahun 2014, Peraturan Menteri Kesehatan No. 19 tahun 2014 dan Surat Edaran Menteri Dalam Negeri mengharuskan Bupati/Walikota untuk segera menetapkan Surat Keputusan Bendahara Puskesmas dan membuka Rekening Dana Kapitasi.

\section{Kondisi Sarana dan Prasarana Puskesmas \\ Pusat Kesehatan Masyarakat \\ (Puskesmas) adalah salah satu sarana pelayanan kesehatan masyarakat yang}


amat penting di Indonesia yang memberikan pelayanan secara menyeluruh, terpadu dan bersinambungan kepada masyarakat dalam suatu wilayah kerja tertentu dalam bentuk usaha-usaha kesehatan pokok dan langsung berada dalam pengawasan administratif maupun teknis dari Dinas Kabupaten (Entjang, 2000). Jika ditinjau dari sistem pelayanan kesehatan di Indonesia, maka peranan dan kedudukan Puskesmas adalah sebagai ujung tombak sistem pelayanan kesehatan di Indonesia. Pemerintah mengembangkan puskesmas dengan tujuan untuk mendekatkan pelayanan kesehatan kepada masyarakat. Berdasarkan Keputusan Menteri Kesehatan RI No. 128/ MENKES/ SK/ II/ 2004 Tentang Kebijakan Dasar Puskesmas mempunyai fungsi sebagai pusat pengerak pembangunan yang berwawasan kesehatan dimana Puskesmas aktif memantau dan melaporkan dampak kesehatan program pembangunan dan pemeliharaan kesehatan pencegahan, penyembuhan dan pemulihan kesehatan melalui pelayanan yang diberikan.

Penempatan sebuah Puskesmas sekarang ini adalah lebih banyak dibangun di ibu kota kecamatan, sedangkan untuk Puskesmas pembantu di tempatkan di desa. Bagi masyarakat atau desa yang maju dengan penduduk yang banyak dapat ditempatkan sebuah Puskesmas, tergantung dari ketersediaan tenaga, khususnya tenaga dokter. Satu hal yang perlu dipertimbangkan terutama adalah ketersediaan tenaga medis dan para medis dan permintaan masyarakat serat keterjangkauannya atau luas wilayah dan jumlah penduduk cukup memadai. Termasuk dalam ketersediaan sarana dan prasarana seperti pengadaan gedung yang layak dan pendistribusian obat-obatan. Sarana dan prasarana kesehatan merupakan bagian yang sangat penting dalam peningkatan mutu pelayanan Puskesmas. Sarana dan prasarana Puskesmas yang lengkap akan berpengaruh terhadap pelayanan pasien. Adapun gambaran secara umum sarana dan prasarana Puskesmas antara lain :

\section{Kondisi Fisik Puskesmas}

Kondisi bangunan pada umumnya memadai, namun beberapa diantaranya kurang perawatan.

\section{Ketersediaan Obat}

a. Puskesmas memiliki apotik, namun belum semua puskesmas memiliki ahli farmasi dalam pelayanan obat.

b. Puskesmas menghadapi masalah ketersediaan obat-obatan yang kurang lengkap/terbatas. Pembelian obatobatan dilakukan oleh Dinas Kesehatan menggunakan dana APBD.

\section{Ketersediaan Peralatan Medis}

Puskesmas memiliki peralatan laboratorium, namun belum lengkap, belum dapat untuk mendukung penegakan 144 diagnosa penyakit secara menyeluruh.

\section{Fasilitas Penunjang}

Operasionalisasi P-Care di 5 Puskesmas (33,3\%) loadingnya sering lambat, yang menyebabkan kelancaran pelayanan kepada pasien terganggu.

\section{Kendala dan Hambatan Pelayanan Kesehatan Program Jaminan Kesehatan Nasional (JKN) di Puskesmas Kota Malang}

Pelaksanaan pelayanan kesehatan program Jaminan Kesehatan Nasional (JKN) di tingkat Puskesmas sebagai Fasilitas Kesehatan Tingkat Pertama (FKTP) masih terdapat beberapa kendala dan keterbatasan, antara lain :

\section{Aspek Pelayanan Puskesmas}

a. Jumlah pasein yang banyak kurang diimbangi dengan ketersediaan SDM Puskesmas mengakibatkan pelayanan menjadi kurang optimal dengan antrian yang panjang dan lama pelayanan kesehatan yang pendek.

b. Desain/layout puskesmas yang bentuk bangunan lama membuat alur pelayanan kesehatan menjadi terputus dan tersekat. 


\section{Aspek Sumber Daya Manusia Puskesmas}

a. Dari sisi ketersediaan SDM pada 15 Puskesmas lokasi penelitian, tidak ada satupun Puskesmas yang memiliki setiap jenis/profesi tenaga kesehatan secara lengkap

b. Persebaran SDM tidak merata.

c. Masih terdapat Puskesmas yang tidak memiliki tenaga dokter gigi.

d. Dari sisi ketersediaan dokter umum berbanding jumlah penduduk wilayah kerja Puskesmas berdasarkan standar Kementerian, yakni 1:1000.

e. Kurangnya SDM khususnya tenaga kesehatan, menyebabkan pelayanan kepada pasien tidak dapat optimal

\section{Aspek Manajemen/Ketatausahaan}

\section{Puskesmas}

a. Puskesmas Kota Malang telah mengoperasikan aplikasi SIM P-Care, namun belum optimal karena keterbatasan perangkat komputer, jaringan internet, dan SDM yang menguasai IT.

b. Dana kapitasi untuk operasional Puskesmas (pembelian obat-obatan, alat kesehatan, alat penunjang, reagen dan lain-lain) di beberapa Puskesmas belum diterima, sehingga Puskesmas tidak dapat dengan segera meningkatkan kapasitas dan kapabilitas pelayanan kesehatannya.

c. Di beberapa Puskesmas, kewenangan pengadaan obat-obatan, pengadaan alat kesehatan alat-alat kesehatan dan alat penunjang lainnya serta BMHP menjadi kewenangan Dinkes, sehingga Puskesmas tidak dapat dengan leluasa membeli sesuai dengan kebutuhan

\section{Aspek Sarana dan Prasarana Puskesmas}

a. Kondisi bangunan Puskesmas pada umumnya memadai, hanya beberapa Puskesmas yang bangunannya sudah tua dan memerlukan perbaikan b. Seluruh Puskesmas menghadapi keterbatasan obat-obatan, laboratorium, dan alat kesehatan, yang menyebabkan pelayanan pengobatan terhadap 144 diagnosa penyakit tidak dapat diberikan secara menyeluruh.

\section{KESIMPULAN DAN SARAN}

Berdasar hasil penelitian, terdapat beberapa kesimpulan antara lain : a) Utilisasi pelayanan Jaminan Kesehatan Nasional di puskesmas wilayah Kota Malang menunjukkan trend meningkat baik kunjungan dan rujukan ke faskes sekunder, tingginya angka rujukan bisa saja menunjukkan kurang berfungsinya peran gate keeeper namun angka rujukan tidak bisa menjadi ukuran tunggal terhadap kualitas gate keeeper. Kondisi faskes dan karakteristik risiko sakit dari peserta yang dibina oleh puskesmas tersebut mempengaruhi angka rujukan, b) Fungsi gate keeper di puskesmas belum optimal yang disebabkan oleh kompetensi dokter layanan primer yang masih belum ditunjang oleh pemahaman yang memadai tentang panduan klinis sebagai acuan dalam pelayanan Jaminan Kesehatan Nasional di puskesmas, serta ketersediaan laboratorium yang lengkap bagi pelayatan kesehata masyarakat. Hal-hal yang perlu sarankan antara lain : a) Pemerintah Daerah perlu meningkatkan kapasitas SDM kesehatan dan menyediakan sarana computer beserta jaringan internet untuk mendukung sistem informasi manajemen (P-Care) dalam rangka peningkatan kecepatan dan ketepatan pelayanan, b) Pemerintah daerah perlu didorong untuk mengalokasikan dana perbaikan pada bangunan Puskesmas yang rusak dan peningkatan sarana prasarana kesehatan di Puskesmas, dan c) Perlunya Kementerian Kesehatan mengambil kebijakan untuk mendorong Pemerintah daerah melakukan penempatan tenaga kesehatan dan non kesehatan di Kota Malang sesuai dengan kebutuhan puskesmas. 


\section{DAFTAR PUSTAKA}

Hasbullah Thabarny, 2014, Sistem Kesehatan (Masih) Sakit, Bahan Paparan Seminar Jaminan Kesehatan, Fakultas Kesehatan Masyarakat Universitas Indonesia, Jakarta

Kementerian Kesehatan, 2012, Peta Jalan Menuju Jaminan Kesehatan Nasional $(J K N)$, Kementerian Kesehatan, Jakarta

Myriad, 2014, Survei Nasional Kepuasan Peserta dan Fasilitas Kesehatan BPJS Kesehatan 2014, Myriad, Jakarta

Mukti, Ali Gufron, 2007, Strategi Terkini Peningkatan Mutu Pelayanan Kesehatan, Konsep dan Implementasi, Pusat Pengembangan Sistem Pembiayaan dan Manajemen Asuransi/Jaminan Kesehatan FK UGM: Yogyakarta

Mukti, Ali Gufron, 2007, Reformasi Sistem Pembiayaan Kesehatan di Indonesia dan Prospek ke Depan, PT. Karya Husada Mukti: Yogyakarta

Mukti, Ali Gufron, 2009, Pengembangan Jaminan Pembiayaan Kesehatan Dalam Kontes Kesejahteraan Minimum: Studi Kasus Di Indonesia. Dipaparkan dalam Seminar Nasional "Kesejahteraan Sosial Minimum" dalam Rangka Dies Natalies Ke 60 UGM

Murti, Bisma, 2010, Strategi untuk Mencapai Cakupan Universal Pelayanan Kesehatan di Indonesia, disampaikan pada Temu Ilmiah Reuni Akbar FKUNS, di Surakarta, 27 November 2010

Normand C, Weber Z, 1994, Social Health Insurance: A guidebook for planning. World Health Organization and International Labour Office: Geneva
Sulastomo, 2014, Sistem Jaminan Sosial Nasional, "Mesin Pembangunan”, Harian Kompas, 7 April 2014, Jakarta

Sulastomo, 2014, Mengevaluasi Jaminan Kesehatan Nasional, Bahan Paparan Rapat Konsultasi Tim SJSN dengan Wakil Presiden, Jakarta

Supriyantoro, 2014, Formulasi Kebijakan Integrasi Jaminan Jesehatan Daerah Ke Sistem Jaminan Kesehatan Nasional Menuju Universal Health Coverage, Desertasi - Universitas Gadjah Mada, Yogyakarta.

TNP2K, 2014, Kajian Kesiapan Puskesmas dalam Pelaksanaan Pelayanan Kesehatan Program Jaminan Kesehatan Nasional, Tim Nasional Percepatan Pengentasan Kemiskinan, Sekretarian Wakil Presiden, Jakarta

World Health Organization, 2010, The World Health Report 2010. Health Systems Financing: the Path to Universal Coverage, World Health Organization,Geneva

World Health Organization, 2007, Everybody Business : Strengthening Health Systems to Improve Health Outcomes : WHO's framework for action

WHO, 2005, Achieving Universal Health Coverage: Developing the Health Financing System. Technical Brief for Policy-makers. Number 1, 2005. World Health Organization, Department of Health Systems Financing,Health Financing Policy

, 2004, Undang-Undang No. 40 Tahun 2014 tentang Sistem Jaminan Sosial Nasional, Kementerian Kesehatan Republik Indonesia, Jakarta 
2013, Peraturan Menteri

Kesehatan No. 71 Tahun 2013 tentang

Pelayanan Kesehatan pada jaminana

Kesehatan Nasional, Kementerian

Kesehatan Republik Indonesia,

Jakarta

2014, Peraturan Menteri

Kesehatan No. 28 Tahun 2014 tentang

Pedoman Pelaksanaan Program

Jaminan Kesehatan Nasional,

Kementerian Kesehatan Republik Indonesia, Jakarta

2014, Peraturan Presiden

No 32 Tahun 2014 tentag Pengelolaan

dan Pemanfaatan Dana Kapitasi

Jaminan Kesehatan Nasional pada fasilitas Kesehatan Tingkat Pertama Milik Pemerintah, Sekretariat Presiden Republik Indonesia, Jakarta

, 2014, PersoalanPersoalan Pelaksanaan Jaminan Kesehatan Nasional, Dewan Pers Jaminan Kesehatan Nasional, Jakarta 